\title{
Interpreting the Shortwave Infrared \& Thermal Infrared Regions of Remote Sensed Electromagnetic Spectrum with Application for Mineral-Deposits Exploration
}

\author{
Yu-Jun Zhang1, Fo-Jun Yao ${ }^{2 *}$ \\ ${ }^{1}$ China Aero-Geophysics and Remote Sensing Center for Land and Resources, Beijing, China \\ ${ }^{2}$ Key Laboratory of Metallogeny and Resources Assessment, Institute of Mineral Resources Chinese Academy \\ of Geological Sciences, Beijing, China \\ Email: zYJ6233@sina.com, ${ }^{*}$ fjyao@sina.com
}

Received 25 November 2014

\section{Abstract}

The ASTER (Advanced Space-borne Thermal Emission and Reflection radiometer) data, including all the 3 parts: VNIR (Visible and Near-Infrared), SWIR (Short Wave Infrared), TIR (Thermal Infrared), were applied for extraction of mineral deposits, such as the Ni-Cu deposit in eastern Tianshan, the gypsum in western Tianshan, and the borax in Tibetan. This paper discusses the extraction methodology using the ASTER remote sensing data and reveals the good extraction results. This paper bravely represents the summary of the main achievement for this field by the scientists in other countries and gives a comparison with the works by others. The new achievements, described in this paper, comprise the extraction of anomalies for $\mathrm{Ni}-\mathrm{Cu}$ deposit, gypsum, and borax.

\section{Keywords}

SWIR (Short Wave Infrared), TIR (Thermal Infrared), RS (Remote Sensing), ETM (Enhanced Thematic Mapper), ASTER (Advanced Space-Borne Thermal Emission and Reflection Radiometer), RS (Remote Sensing), EMR (Electromagnetic Radiation), SAM (Spectral Angle Mapper)

\section{Introduction}

Since the appearance of ASTER in Dec. 1999, the use of ASTER data in mineral prospecting has increased in recent years because of its relatively low cost, broad coverage, and unique integral bands highly sensitive to alteration minerals (i.e. minerals known to surround target minerals). The ASTER data set contains visible, shortwave infrared and thermal bands. Because the spectral bands of ASTER are sensitive to absorption of some minerals. The proper preprocessing and combination of these bands can produce relative mineral alteration distributions such as illite, alunite, kaolinite, carbonates and so on. Kanlinowski and Oliver [1] offered a suite of

\footnotetext{
*Corresponding author.
}

How to cite this paper: Zhang, Y.-J. and Yao, F.-J. (2015) Interpreting the Shortwave Infrared \& Thermal Infrared Regions of Remote Sensed Electromagnetic Spectrum with Application for Mineral-Deposits Exploration. Journal of Applied Mathematics and Physics, 3, 254-261. http://dx.doi.org/10.4236/jamp.2015.32037 
standard ASTER alteration enhancements that can be used to broadly delineate these alteration mineral zones or assemblages.

Since then the remote sensing anomaly technology has been spread throughout the country. By the same time our research effort was concentrated on the application of ASTER data for resolving the problems, left with ETM, on the classification of remote sensing anomalies, on the anomaly extraction of new mineral types. We have developed a simplified algorithm for temperature and emission separation using de-correlation stretch function, proposed at first by Gilespie, et al. in 1998 [2]. Up to now we've got anomalies of mineral 12 types [3]. Here the anomaly extraction of mineral deposits will be explored. In comparison with the works by others in this field, our new achievements comprise the extraction of anomalies for $\mathrm{Ni}-\mathrm{Cu}$ deposit, gypsum, and borax.

\section{Spectroscopy for Remote Sensing in Geological Application}

\subsection{Visible-Reflected Infrared Remote Sensing}

Spectroscopy for RS may be defined as the study of the interaction of earth matter with electromagnetic radiation. The regions of the RS EMR for geological work with goal in detection and exploration of mineral resources are visible $(0.35-0.70 \mu \mathrm{m})$, near-infrared and SWIR $(0.7-2.5 \mu \mathrm{m})$, TIR $(8-13 \mu \mathrm{m})$ (see Table 1). Within these ranges, intrinsic interactions are caused by electronic and/or vibrational processes.

For geologic materials, electronic processes provide information about the presence and nature of a particular iron and its environment, about adjacentions, or about defects in specific crystal locations. Thus, information concerning bulk composition is of an indirect nature.

Vibrational processes are governed by three characteristic properties of the material: the chemical composition, the geometry and equilibrium positions of the constituent atoms, and potential field of the interatomic

Table 1. Discrimination of deposit types by multi-channel r.s.

\begin{tabular}{|c|c|c|c|c|c|c|c|c|c|c|c|c|}
\hline \multirow{3}{*}{ No } & \multicolumn{3}{|c|}{ ETM } & \multicolumn{3}{|c|}{ OHA-ASTER-SWR (Microns) } & \multicolumn{5}{|c|}{ ASTER-TIR (Microns) Emission } & \multirow[t]{2}{*}{ Examples } \\
\hline & & OHA & FCA & 5.6 & 7.8 & 9 & 10 & 11 & 12 & 13 & 14 & \\
\hline & & & & $2.145-2.225$ & $2.235-2.365$ & $2.36-2.43$ & $8.125-8.475$ & $8.475-8.825$ & $8.925-9.275$ & $10.25-10.95$ & $10.95-11.65$ & \\
\hline 1 & $\begin{array}{l}\text { Porphyry } \\
\text { copper }\end{array}$ & $\mathbf{H}$ & $\mathbf{H}$ & $\mathbf{H}$ & & & & & $\mathbf{R L}$ & & & 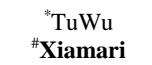 \\
\hline 2 & $\begin{array}{c}\text { Skarns } \\
\text { Pb-Zn, Cu }\end{array}$ & $\mathbf{H}$ & & & $\mathbf{H}$ & & & & & & $\mathbf{L}$ & ${ }^{*}$ ShaQuanZi \\
\hline 3 & $\begin{array}{c}\text { Ultra-basic } \\
\text { Cu-Ni, Ni }\end{array}$ & $\mathbf{H}$ & & & $\mathbf{H}$ & & & & & XL & & $\begin{array}{l}{ }^{*} \text { Huangshan } \\
{ }^{\wedge} \text { LuoDong }\end{array}$ \\
\hline 4 & Carbonate & $\mathbf{H}$ & & & $\mathbf{H}$ & & & & & & XL & * \\
\hline 5 & Smithsonite & & & & $\mathbf{H}$ & & & & & & XL & $\begin{array}{l}{ }^{*} \text { Chaqu } \\
\text { Pa Cha }\end{array}$ \\
\hline 7 & Celestine & & & $L:((-11)$ & $-(-10 \%))$ & & RL & XL & & & & ${ }^{*}$ Da Feng shan \\
\hline 8 & Boron min. & & & $\begin{array}{c}(8 \%-7 \%) \\
6 \%+\end{array}$ & $\begin{array}{l}\text { BS (8\% } \%- \\
0-5 \%)\end{array}$ & & & & & & & *Bankog Co \\
\hline 9 & Sederite & $\mathbf{H}$ & & $(29 \%-28 \%$ & $24 \%-25 \%)^{* 3}$ & & & & & & & *Guanyinshan \\
\hline 10 & Kaolinclay & $\mathbf{H}$ & & & & & & & & & XL & *Jingdezhen \\
\hline 11 & Iron ore & & $\mathbf{H}$ & & & & & & & & & ${ }^{*}$ Abagong \\
\hline 12 & $\begin{array}{c}\text { Porcelain } \\
\text { clay }\end{array}$ & $\mathbf{H}$ & & & & & & & & & & Jingdezhen \\
\hline & Remarks & & Thi & $\begin{array}{l}\text { s table was con } \\
\text { Zhang in } 1992 \\
\text { H-high; L- }\end{array}$ & $\begin{array}{l}\text { ucted by } \\
12 \mathrm{y} \text {. } \\
\text { ow }\end{array}$ & & $\begin{array}{r}\text { Luo } \\
\text { \& Xiamari } \\
\text { XI }\end{array}$ & $\begin{array}{l}\text { Dong Ni depos } \\
\text { i Cu deposits } \\
\text {-extremely }\end{array}$ & $\begin{array}{l}\text { sits, ShaQuanZ } \\
\text { vere discovered } \\
\text { ow; RL-relati }\end{array}$ & $\begin{array}{l}\text { i Pb-Zn } \\
\text { l by our work. } \\
\text { ve low }\end{array}$ & & $\begin{array}{l}{ }^{*} \text { Tianshan } \\
{ }^{\#} \text { Gangdisi } \\
{ }^{\wedge} \text { Beishan }\end{array}$ \\
\hline
\end{tabular}


forces representative of inter-atomic bonds and angles. Consequently the information available is directly related to bulk composition.

Rocks are basically assemblages of minerals. So much of our referred spectra presented by USGS and ASU are mostly for pure minerals since the spectrum of a rock is typically some composition of the spectra of its constituent minerals.

So the inverse problem is usually quite complicated. Nevertheless we have succeeded in extracting RS anomalies of 12 different types of mineral deposits (Table 1).

\subsection{Thermal Infrared Remote Sensing}

Thermal infrared spectral range of 8 - $13 \mu \mathrm{m}$, the thermal infrared spectra in the ASTER data include information of temperature and emissivity. In order to geological applications, it's necessary to get the thermal infrared spectral emissivity. The method "discrimination method of extremes on the spectral shape" was applied based on de-correlation stretch (or transformation) in this paper. The information of carbonate, sulphate, and ultrabasic rocks were extracted.

\section{Processing Techniques of ASTER Images}

The ASTER data (all of the Visual-near Infrared, the Short Wave IR and the Thermal IR) were used for the extraction of R.S. anomaly for the hydroxyl minerals in hydrothermal alteration zone of metallic ore deposit , the carbonaceous (marble, smithsonite, dolomite, calcite) and sulfates (gypsum, celestine) sediments.

\subsection{De-Interfered Anomalous Principal Component Thresholding Technique}

The early use of PCA for extraction of TM anomaly was made by Crosta and Moore [4] and Loughlin [5]. Then we expanded its use for ASTER data [6]-[9]. An advanced system for extraction of hydrothermal alteration assemblages from ETM+ and Aster data, "De-interfered Anomalous Principal Component Thresholding Technique”, is illustrated in Figure 1. The RM, SAM and PCA are compared by the analysis of their principles and the modeling test. The pre- and post-processing have been done for limiting the interference of water, ice, cloud, snow, vegetation, relief shadow, cloud shadow, salt-lick.

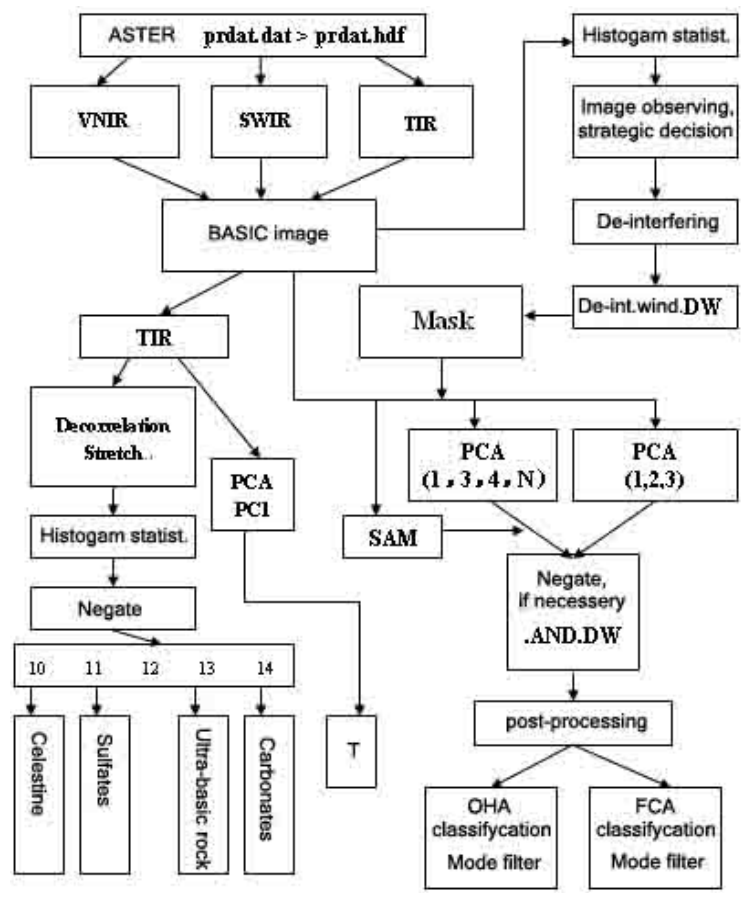

Figure 1. De-interfered anomalous principal component thresholding technique. 


\subsection{Discrimination Method of Extremes on the Spectral Shape}

The ASTER data (all of the Visual-near Infrared, the Short Wave IR and the Thermal IR) were used for the extraction of R.S. anomaly for the carbonaceous (marble, smithsonite, dolomite, calcite) and sulfates (gypsum, celestine) sediments. The main processing techniques used are:

- The De-correlation Stretch (or transformation);

- The Band-Selective Principle Component Analysis (PCA);

- The Combinatorial(combinational) Band Ratio Analysis;

- The Relative Band Depth (RBD);

- The Piece-Wise Thresholding.

The De-correlation stretch is especially effective on ASTER-TIR images in which channels are highly correlated by temperature. De-correlation is used for separation of temperature and thermal emission (see Figure 2).

\section{The Discovery of Luodong Ni Deposit}

Using these techniques we have inversed quite a lot science of ETM + and ASTER data and gained high quality result. For example we take the discovery of Luodong Ni deposit, the determination of gypsum, and the determination of borax .

\subsection{The Discovery of Luodong Ni Deposit}

Figure 3 shows the complex information for discovery of Luodong deposit in Ruoqiang county of Xinjiang. For discrimination of the ETM+ anomaly characteristic, the SAM was used in interpretation. The spectrum data of Poshi known small Ni deposit was taken as a reference spectrum. The inversion result was verified by field work, PIMA determination and electro-probing.

\subsection{The Determination of Gypsum}

Owing to the severe shortage of potash fertilizer in China, great attention has been paid to make full use of achievements of geophysics and remote sensing in exploration of potash salt in China during the past more than 50 years. Because of the lacking of diagnostic spectral property for potash salt, we tried to use the gypsum for indirect path for this problem.

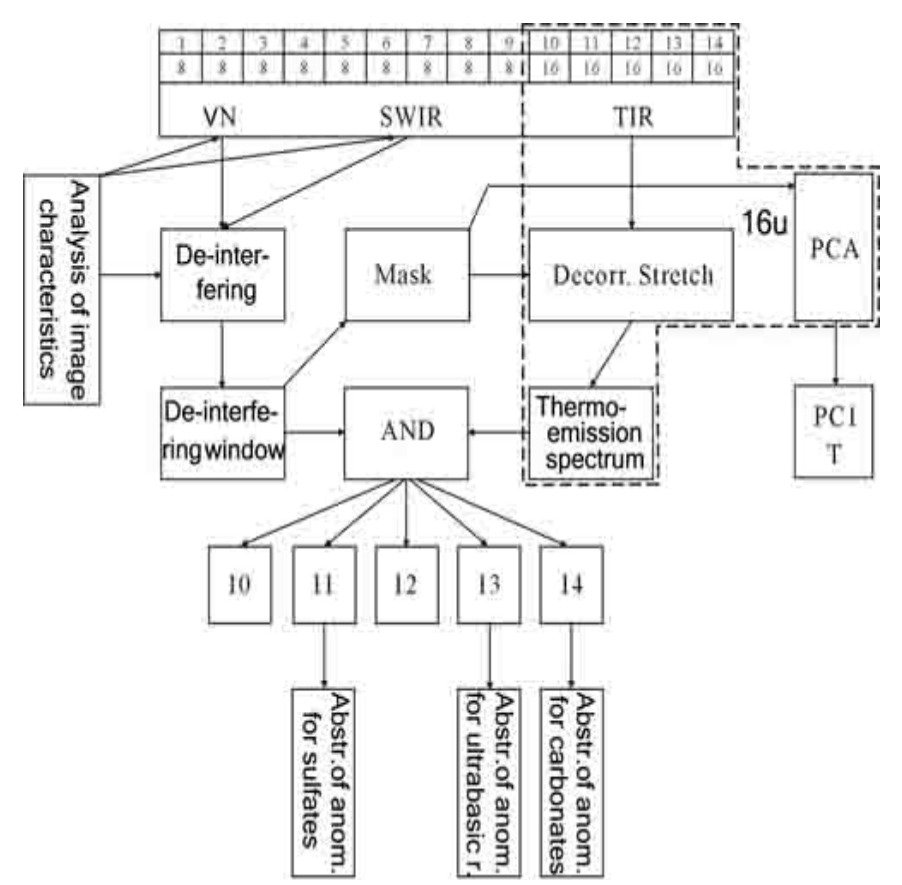

Figure 2. Flow-chart for ASTER-TIR. 


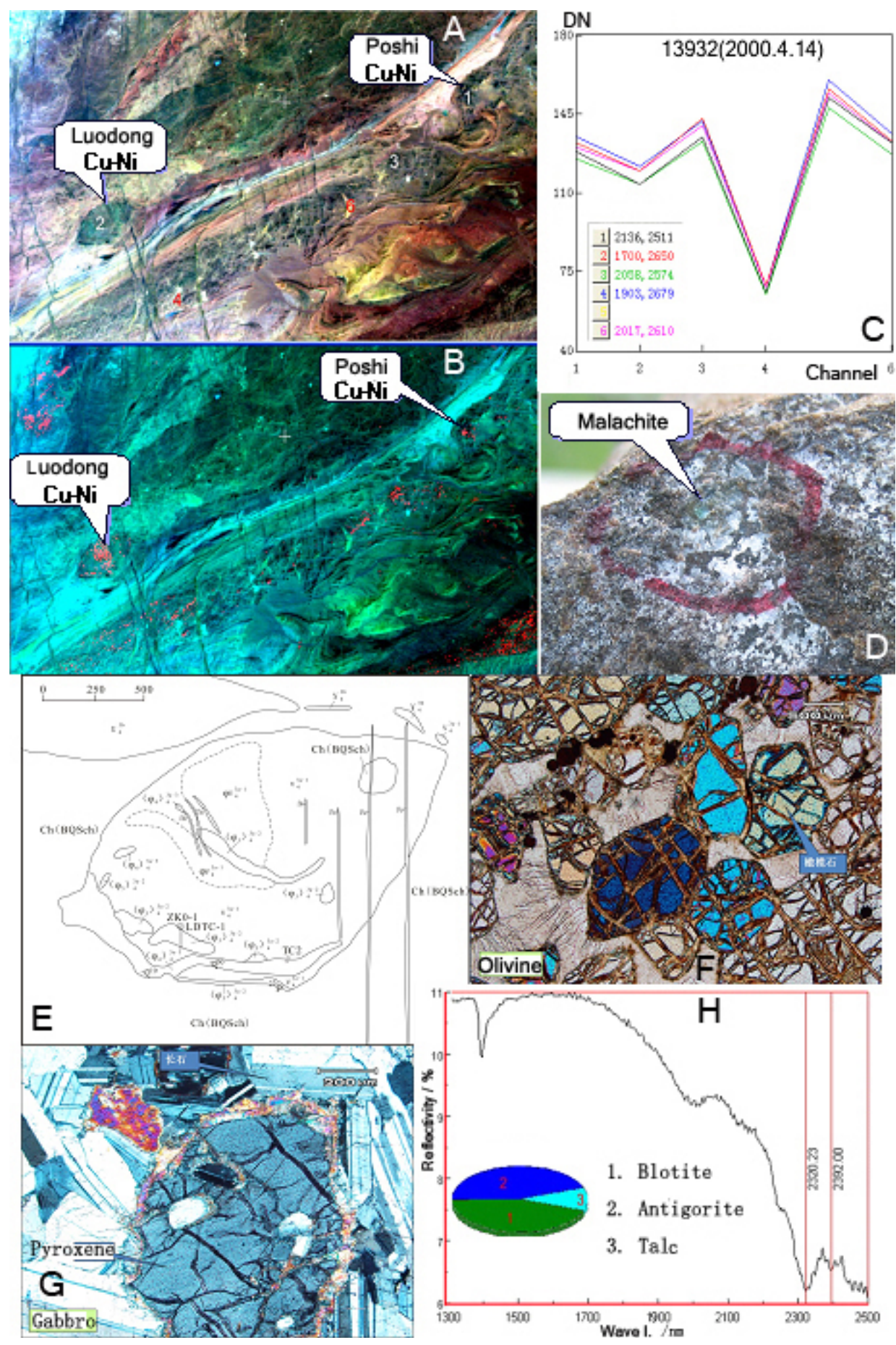

Figure 3. Complex information for discovery of Luodong deposit. (A) RS image; (B) RS anomaly image; (C) Spectra; (D) Photo of rock; (E) Simplified geological map; (F) Microscopic photo of olivine; (G) Microscopic photo of gabbro; (H) PIMA result.

The specific spectral characteristic for gypsum shown in Figure $\mathbf{4}$ is displaying one example of determination of gypsum by processing of ASTER-TIR data using flow-chart in Figure 2. This interpretation method was used for Qiangtang Basin, where the condition is quite severe for field geologic work. The average elevation is $>5000$ $\mathrm{m}$; the air is very thin; it is extremely cold. The basin is almost a restricted zone. So the application of remote sensing for geological work in this kind of area is especially important. 

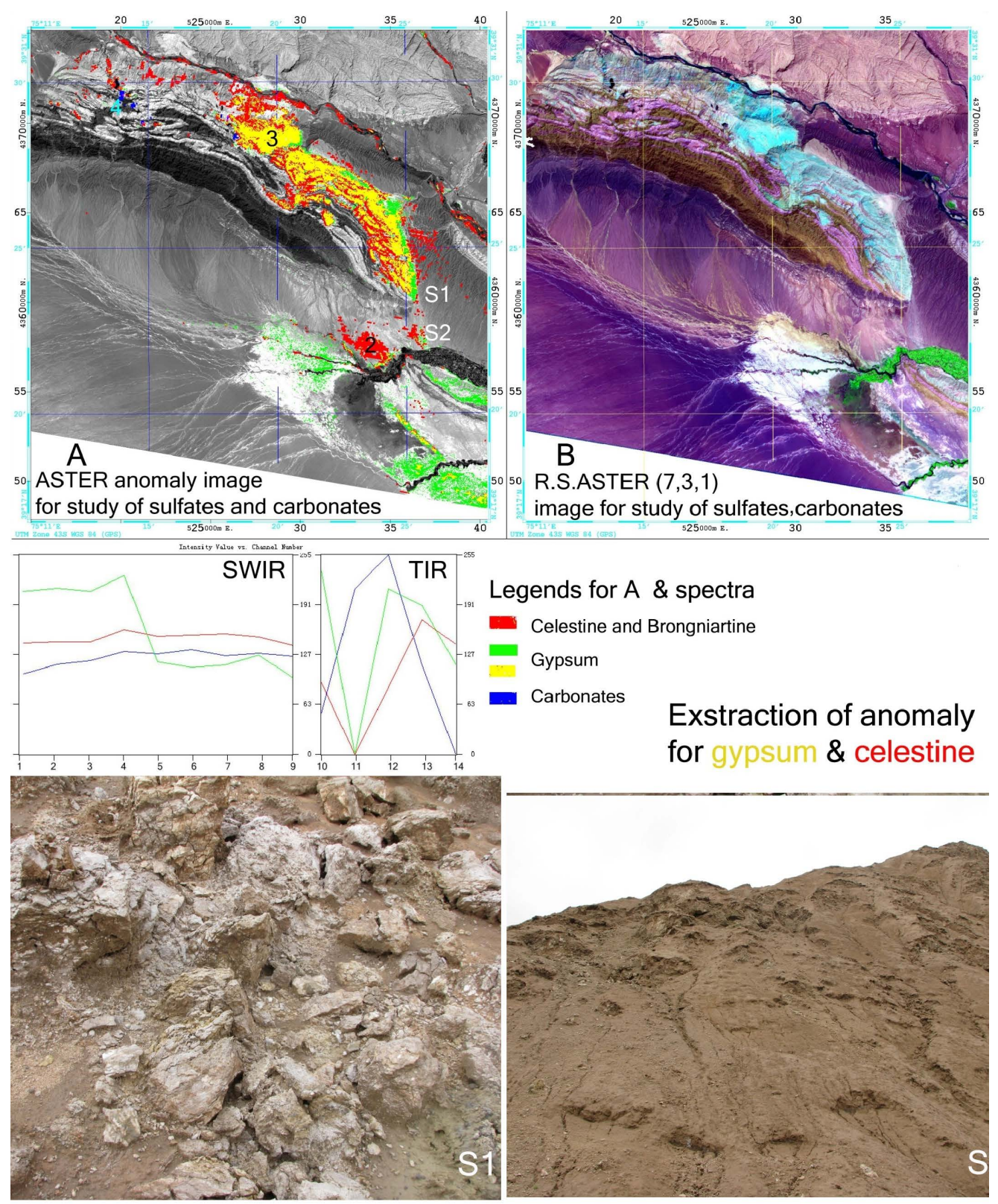

Figure 4. (A) ASTER anomaly image; (B) ASTER image (7, 3, 1); S1. Photo, taken of point s1 in (A), showing gyosum; S2. Photo of point S2 in (A), showing gypsum covered by mud.

\subsection{The Determination of Borax}

The usage of borax on Qinghai-Tibet Plateau for medical, glazier and other purposes takes special role. The exploitation of borax is one of the important component parts of Tibetan industry all along. BanKogCo was taken as a known borax deposit for the application of ASTER data. BanKogCo belongs to the moderately mineralized carbonate type. It is located $10 \mathrm{~km}$ in the east from SilingCo or $120 \mathrm{~km}$ in the north-east from the famous NamCo as the biggest saline lake in Tibet. BankogCo consists of 3 small lakes. The sedimentary sub-environment in BankogCo district is shown in Figure 5 [10].

The Combinatorial Band-Ratio Analysis of the SWIR was studied for the borax anomaly and to avoid the false anomaly from carbonates and argillaceous sediments. Besides BanKogCo the borax anomaly appears at the east of NamkaCo. This region is an undiscovered area. Since the anomaly is even stronger than that for BanKogCo, it is worth carrying on exploration after some ground truth investigations (Figure 6). 


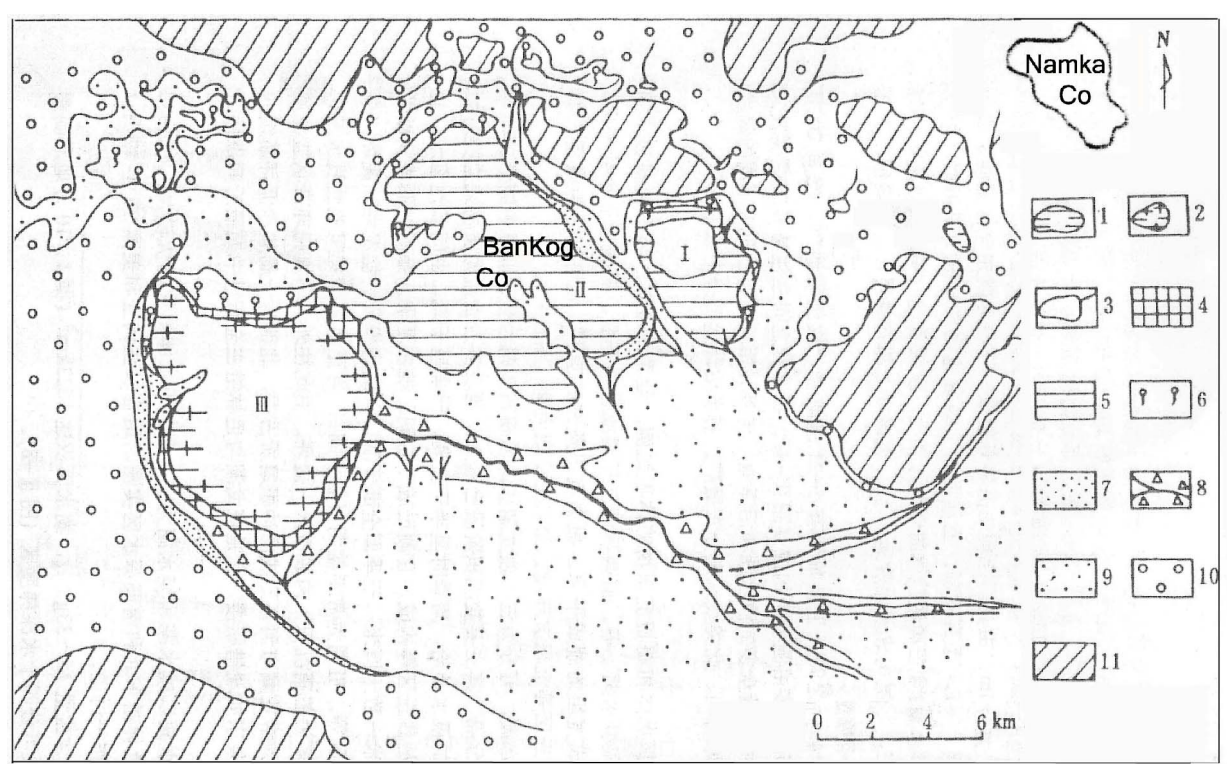

Figure 5. Sedimentary sub-environment in BanKogCo district [10]. Perennial brackish lake; 2-Perennial saline-lake; 3-Ephemeral lake; 4-Salt pan; 5-Salt mud-flat; 6-Spring pond-marsh; 7-Sand flat; 8-Alluvial fan; 9-Bench and strand; 10-Bench pad and platform bench; 11-Bed rock.

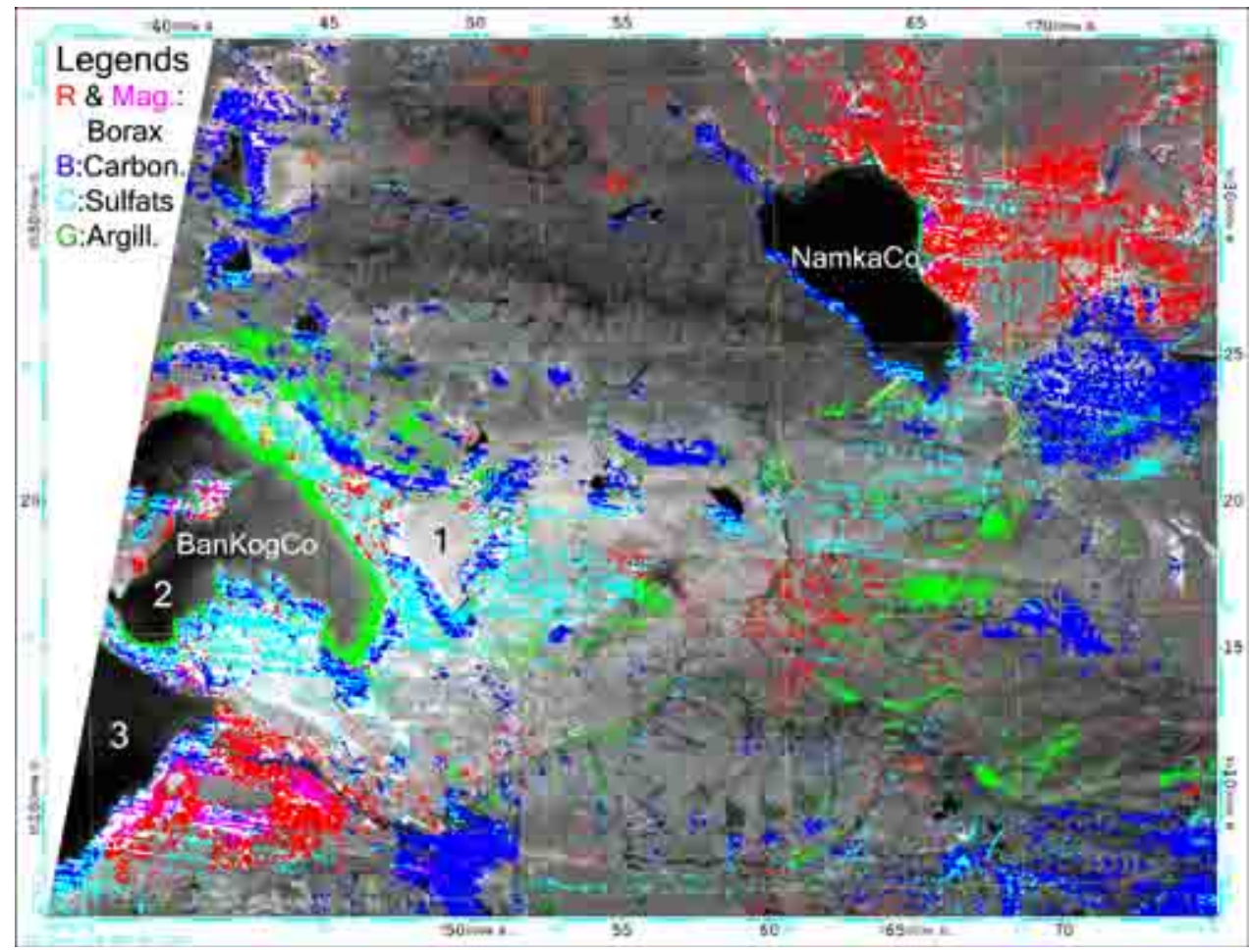

Figure 6. Results of processing of ASTER image for BanKogCo.

\section{Acknowledgements}

This research was jointly supported by National Natural Science Foundation of China (No. 41102205), Special Funds Projects for Basic Scientific Research Business Expenses of Mineral Resources Research Institutes in Chinese Academy of Geological Sciences (Nos. K1208, K1213). We thank greatly Prof. Yang Jianmin for Field work in discovery of Luodong Ni Deposit. 


\section{References}

[1] Kanlinowski, A. and Oliver, S. (2004) ASTER Mineral Index Processing, Remote Sensing Application, Geo-Science Australia, Internal Report, 39 p. http://www.ga.gov.au/image cache/GA7833.pdf

[2] Gilespie, A., Rokugawa, S., et al. (1998) A Temperature and Emissivity Separation Algorithm for Advanced SpaceBorne Thermal Emission and Reflection Radiometer (ASTER) Images. IEEE Transactions on Geo-Science and Remote Sensing, 36, 1113-1126. http://dx.doi.org/10.1109/36.700995

[3] Zhang, Y.J., Yang, J.M., Yao, F.J., Geng, X.X. and Yu, X.Z. (2014) Practical Techniques for Exatraction of Ore Exploration Information from Multi-Spectral Remote Sensing Data. Geological Publ. House, Beijing.

[4] Crosta, A.P. and McM Moore, J. (1989) Enhancement of Landsat Thematic Mapper Imagery for Residual Soil Mapping in SW Minais Gerrain. Proceedings of the 7th (ERIM) Thematic Conference: Remote Sensing for Exploration Geology Calgary, 1173-1187.

[5] Loughlin, W.P. (1991) Principal Component Analysis for Alteration Mapping. Proceedings of the 8th Thematic Conference on Geologic Remote Sensing, Denver, 293-306.

[6] Zhang, Y.J., Zeng, Z.M. and Chen, W. (2003) The Methods for Extraction of the Alteration Remote Sensing Anomaly from ETM+(TM) Data and Their Application: Method Selection and Technological Flow-Cart. Journal of Remote Sensing for Land \& Resources, 2, 44-49. (In Chinese with an English Abstract)

[7] Zhang, Y.J. and Yang, J.M. (2005) A New Exploration Parameter for Metallic Deposits-Alteration Remote Sensing Anomaly. Mineral Deposit Research: Meeting the Global Challenge, 2, 1513-1516.

[8] Zhang, Y.J. and Yao, F.J. (2009) The Application Study of Multi-Spectral ASTER Data for Determination of ETM Remote Sensing Anomaly Property-Taking Eastern WuLongGou Region of KunLun Mountain Range as Example. Acta Petrologica Sinica, 25, 963-970.

[9] Zhang, Y.J., Liu, C.L., Yao, F.J., Liu, C.Z. and Li, M.X. Extraction of ASTER R.S. Anomalies for Sedimentary Deposits in Qaidam Basin, as the Test Field for Mars. Proceedings of 2009b Beijing Lunar Science Workshop, 11-15.

[10] Zheng, M.P., et al. (1989) Saline Lakes of Qinghai-Tibet Plateau. (In Chinese) 